\title{
ANÁLISE COMPARATIVA ACERCA DA UTILIZAÇÃO DE DESENHOS NA PESQUISA SOBRE A CRIAÇÃO DO SENTIDO DA MUDANÇA ORGANIZACIONAL
}

\author{
Autores: \\ José Roberto Gomes da SILVA, Doutor, Pontifícia Universidade Católica do Rio de Janeiro, \\ IAG/PUC-Rio. \\ Sylvia Constant VERGARA, Doutora, Escola Brasileira de Administração Pública e de \\ Empresas - EBAPE, Fundação Getulio Vargas.
}

\section{RESUMO}

Uma das principais críticas que são dirigidas a muitas das pesquisas que procuram obter uma melhor compreensão sobre o fenômeno da mudança organizacional, tão presente em nossos dias, é o emprego de metodologias de investigação que colocam um foco predominante sobre as iniciativas de natureza institucional para a gestão da mudança, minimizando a importância do sentido atribuído pelas pessoas da organização.

Assim também, as metodologias dominantes pouco têm contribuído para que se possa obter uma maior compreensão sobre o modo como as pessoas e equipes na organização lidam com os aspectos de natureza afetiva, psicológica e social envolvidos nas situações de mudança.

O presente trabalho tem como objetivo lançar um olhar mais atento sobre o emprego de uma metodologia de investigação que procura resolver em parte algumas dessas questões: a aplicação da dinâmica de construção de desenhos, que busca compreender o processo de criação de sentido da mudança.

Para tanto, dois estudos que empregaram esse tipo de método de investigação são analisados de forma comparativa: um estudo realizado no Reino Unido por Vince e Broussine (1996) e outro realizado no Brasil, por Silva e Vergara (1999).

\section{A Problemática da Investigação Sobre a Mudança Organizacional}

A mudança organizacional é, seguramente, um dos temas que mais têm despertado o interesse dos teóricos da administração nas últimas décadas, o que tem produzido uma quantidade considerável de reflexões, análises e proposições de soluções com relação à problemática de como ajudar as organizações a efetuarem mudanças de modo eficaz e menos traumático para elas e para seus empregados.

Entretanto, a dificuldade de se compor um corpo teórico integrado e as experiências nem sempre bem sucedidas, em termos da aplicação dessas teorias, têm provocado o crescimento do volume de críticas a elas dirigidas. Entre tais críticas, destacam-se as de que:

- existe uma diversidade de abordagens com foco limitado sobre a mudança organizacional e a dificuldade de conciliação entre essas diferentes abordagens, de modo a produzir um corpo de conhecimento mais integrado que auxilie na definição de ações melhor adaptáveis a cada tpo de mudança (Armenakis e Bedeian, 1999; Van de Ven e Poole, 1995; Weick e Quinn, 1999); 
- muitas de tais abordagens refletem conceitos oriundos do mesmo paradigma instrumental, o que faz com que pouco desenvolvimento adicional tenha sido acrescentado para o entendimento da mudança (Weick e Quinn, 1999);

- grande parte dos estudos focaliza a mudança apenas em um nível macro, sob a ótica de como ela é concebida pelo dirigente, sem levar suficientemente em conta como é vivida e apropriada pelos outros membros da organização que participam da ação (Giroux e Dumas, 1997; Giroux, 1993; Taylor, 1993; Demers, 1993);

- pouca atenção tem sido dada ao sentido, aos custos e às conseqüências humanas da mudança, ou seja, ao que ela representa e como ela afeta os indivíduos que dela participam (Armenakis e Bedeian, 1999; Kets de Vries e Balazs, 1999; Rouleau, 1999,2).

No campo da Administração, os estudos sobre a gestão das mudanças organizacionais têm optado, de modo predominante, por abordar essa temática segundo um foco centrado nas iniciativas institucionais da organização, que visam à compreensão e ao engajamento das pessoas (ex.: Allaire e Firsirotu, 1989; Clarke e Garside, 1997; Kotter, 1995; Nadler, 1989).

Entretanto, nas últimas décadas observa-se a emergência de um enfoque inspirado nas pesquisas na área das ciências sociais, que têm procurado ampliar essa compreensão sobre a lógica da construção da mudança. Tal enfoque incorpora a idéia de que mudança é algo que se produz não apenas por meio das diretrizes e ações institucionais implementadas, mas em grande parte nas interações do dia-a-dia, à medida que a organização se constrói continuamente, como um contexto social. Tal forma de abordar a mudança organizacional é observada, por exemplo, nos estudos de Ford e Ford (1995), Giroux (1993), Taylor (1993) e Weick (1995), bem como pelos diversos seguidores da Teoria da Estruturação de Giddens (1984).

Nesse último tipo de abordagem, um dos focos principais da pesquisa sobre a mudança organizacional passa a ser a compreensão do processo pelo qual ela se constrói em termos de seu significado, seu sentido para as pessoas, como uma espécie de reconstrução coletiva da visão de mundo e das identidades daqueles que participam desse processo. Buscando focalizar a comunicação como um elemento central, como uma arena na qual o sentido da mudança se constrói efetivamente, Taylor (1993) utiliza, por exemplo, a imagem da interação entre um texto organizacional, representado pelas crenças, definições e iniciativas institucionais, e uma conversação, que se desenvolve no dia-a-dia em torno desse texto e que, ao mesmo tempo, o modifica.

Em termos metodológicos, a pesquisa acerca desse processo de construção do sentido da mudança requer a aplicação de formas de investigação que privilegiem a escuta e a observação das percepções individuais e coletivas, bem como os mecanismos de natureza consciente e inconsciente que participam da construção da ação organizacional.

Segundo Giddens (1997, 1993), isso pressupõe um novo tpo de programa para a pesquisa sociológica aplicável ao estudo das estruturas sociais, entre elas as organizações, no qual se considere que:

- a sociologia não está preocupada com o universo pré-concebido de objetos, mas com aquele que é constituído ou produzido pela ação dos sujeitos; 
- a produção e reprodução da sociedade deve ser tratada como um desempenho competente de seus membros e não como uma série de processos meramente mecânicos, o que não significa afirmar que os atores sejam, necessariamentte, totalmente conscientes dessas competências e de como eles as gerenciam;

- os seres humanos constituem uma sociedade, mas eles o fazem como atores localizados historicamente e não sob condições de sua própria escolha. Giddens identifica, no entanto, que há uma margem instável entre condutas que podem ser analisadas como ação intencional e comportamentos que podem ser analisados nomologicamente, como um conjunto de ocorrências. Com relação à sociologia, a tarefa crucial da análise nomológica deve ser concentrada na explanação das propriedades estruturais dos sistemas sociais;

- a estrutura precisa ser conceitualizada não simplesmente como algo que coloca restrições à ação humana, mas como algo que também é por ela habilitada; a estrutura pode sempre, em princípio, ser examinada em termos de sua estruturação. Investigar a estruturação das práticas sociais significa procurar a explicação de como essa estrutura é constituída por meio da ação e, reciprocamente, como a ação é constituída estruturalmente;

- os processos de estruturação envolvem um jogo compartilhado (interplay) de significados, normas e poder;

- o observador sociológico não pode fazer da vida social um fenômeno disponível para observação independentemente de construir seu conhecimento sobre ela. Nesse sentido, a posição do observador não é diferente da posição de qualquer membro da sociedade; sociólogos e atores sociais utilizam o mesmo conhecimento mútuo, os mesmos esquemas interpretativos para fazer sentido sobre a atividade social;

- a imersão em uma forma de vida social é o único meio que torna o observador apto a gerar tais categorizações. Giddens ressalta, no entanto, que essa imersão não significa que o pesquisador precisa tornar-se membro da cultura, mas sim de que precisa estar apto a participar de um conjunto de práticas que precisam ser traduzidas para o discurso científico.

\section{A Organização Vista Sob a Ótica do Significado}

Walsh e Ungson (1991) definem a própria organização como uma rede de significados ou de sentidos compartilhados intersubjetivamente, que são sustentados pelo desenvolvimento de uma linguagem comum e pelas interações do dia-a-dia.

De acordo com Taylor(1993), o conceito de organização é uma abstração. Uma organização não pertence ao mundo material já que ela não corresponde ao domínio dos objetos que podemos tocar, ver, entender, cheirar, degustar, ou, de uma maneira geral, perceber pelos sentidos. Ela pertence ao universo dos objetos imaginados.

Um objeto imaginado não é necessariamente menos real do que um objeto fisicamente presente aos nossos sentidos, mas sua apreensão apresenta um problema de ontologia e epistemologia: o problema não é somente de poder visualizar, conceituar, mas também de poder verificar por evidências concretas as propriedades de um objeto que não deve a sua existência senão à imaginação. E mais: no cotidiano, é a abstração imaginária que evolui, não a realidade. 


\section{A Análise do Processo de Interpretação e Construção do Sentido da Mudança}

A dimensão consciente dos indivíduos com relação à mudança organizacional está diretamente associada ao modo como eles constróem a sua interpretação sobre ela e, como consequiência, ao modo como o significado da mudança é construído por cada indivíduo, dentro do contexto coletivo do qual participa.

Diferentes autores têm se dedicado a estudos de natureza interpretativa, ou seja, que visam obter uma melhor compreensão sobre o processo de interpretação da mudança e de sua construção de significado. Isabela (1990) identifica um conjunto de premissas importantes, que têm sido assumidas por tais estudos, cujo foco principal tem sido a lógica cognitiva desenvolvida pelos participantes de um determinado contexto de mudança:

- os membros da organização criam ou ordenam ativamente a realidade da qual participam;

- em uma coletividade, existem quadros de referência que os indivíduos podem compartilhar;

- as visões dos gerentes sobre a mudança demonstram ser especialmente relevantes nesse processo, uma vez que eles parecem ser o coração das trocas cognitivas que ocorrem durante a mudança organizacional;

- as interpretações dos eventos de mudança são feitas a posteriori, com relação aos eventos sobre os quais elas são construídas.

A autora identifica, ainda, que as pessoas desenvolvem as suas interpretações sobre os eventos da mudança, por meio de um processo que compreende quatro estágios:

Antecipação: é o estágio no qual as pessoas recolhem os rumores ou outros fragmentos de informação, na tentativa de construir um quadro de referência;

Confirmação: durante esse estágio, o quadro de referência construído é reforçado por explicações e comparações a eventos passados;

Culminação: corresponde ao estágio no qual as pessoas comparam as condições anteriores e posteriores a um evento e procuram um significado simbólico;

Resultado: $\quad$ é o estágio no qual as pessoas revêem as conseqüências do evento.

De modo a compreender esses quatro estágios do processo de interpretação, com os gerentes de uma empresa que havia passado por uma mudança significativa, Isabela (1990) utilizou em seus estudos uma metodologia de investigação compreendendo:

a) a identificação da sequiência de eventos relevantes que caracterizaram a mudança, o que foi feito por meio de entrevistas com quatro gerentes de níveis organizacionais distintos, nas quais cada gerente deveria identificar os eventos por eles considerados mais críticos;

b) entrevistas com gerentes de diferentes níveis organizacionais, selecionados para a amostra de pesquisa, de modo a identificar sua história na empresa, suas experiências e suas percepções sobre os valores e crenças significativos da companhia; 
c) entrevistas semi-abertas, com o mesmo grupo de gerentes mencionados em (b), de modo que eles pudessem relatar suas percepções acerca da seqüência de eventos que marcaram a mudança da organização.

Weick (1995) faz uma síntese das principais características em comum encontradas nos estudos mais recentes sobre a criação de sentido nas organizações:

- os investigadores fazem um esforço para preservar a ação que é situada no contexto; onde o contexto é simulado, são feitas tentativas de se reter a riqueza do contexto de referência; ambas as abordagens são complementadas por explicações que implicam interações ou transações do tipo pessoa-situação;

- os observadores confiam menos em medidas específicas de pesquisa e mais naquilo que os participantes dizem e fazem; os textos dos participantes são vistos como fundamentais;

- os observadores trabalham in loco mais do que em seus escritórios;

- são os participantes, mais do que os pesquisadores, que definem o ambiente de trabalho;

- as constatações são descritas mais em termos de padrões do que de hipóteses;

- as explicações são testadas mais com base no senso comum e na plausibilidade, do que em teorias a priori;

- a densidade da informação e a vivacidade do significado são tão cruciais quanto a precisão e a replicabilidade;

- tende a haver uma maior valorização de um exame intensivo de um pequeno número de casos do que um exame seletivo de um grande número de casos, com base no pressuposto de que as interações do tipo pessoa-situação tendem a ser similares entre classes de pessoas e situações;

- a criação de sentido tende a ser especialmente visível nos locais observados. Os locais são escolhidos mais pela possibilidade de acesso ao fenômeno do que pela sua representatividade;

- os observadores mobilizam um conjunto de táticas metodológicas que permitem lidar mais com significados do que com contagens de frequiência. As metodologias são montadas a serviço do ganho de acesso à geração de algum tipo de explicação para as interrupções inesperadas.

\section{A Motivação dos Atores e a Utilização de Desenhos como Processo de Investigação}

Vince e Broussine (1996) ressaltam que uma das grandes dificuldades de se compreender o modo como os indivíduos atribuem significado ao contexto da mudança é a de que grande parte das metodologias utilizadas enfatiza somente uma dimensão racional, deixando de lado os aspectos de cunho emocional, psicológico e político.

Tais autores percebem que a utilização de uma metodologia que envolva a criação de desenhos ajuda os indivíduos e grupos a expressarem mais facilmente essas outras dimensões envolvidas em suas percepções, as quais eles não expressariam de modo mais racional. Segundo esses autores, o uso de desenhos pode ser posicionado metodologicamente na gama de abordagens qualitativas de pesquisa humana que têm sido denominadas como pesquisa 
colaborativa, na medida em que assumem como pressuposto que a pesquisa é um processo conduzido com as pessoas e não sobre elas.

\section{O Objeto da Presente Análise}

Seguindo essa lógica, Vince e Broussine (1996) realizaram uma pesquisa com um grupo de gerentes de seis empresas do setor público no Reino Unido, na qual aplicaram uma metodologia que incluía a elaboração de desenhos por cada um dos participantes, seguida de uma discussão coletiva, com o objetivo de colher seus sentimentos e percepções sobre o contexto de mudanças que vinha sendo observado.

Seguindo princípios semelhantes, porém com a aplicação de uma dinâmica de criação coletiva de desenhos, Silva e Vergara (1999) realizaram um outro estudo em uma grande empresa estatal brasileira do setor elétrico.

A seguir, apresenta-se a síntese comparativa das principais características e resultados obtidos em cada estudo. A análise que se segue procura comparar as características e resultados desses dois estudos, com o objetivo de apreender uma melhor percepção sobre a validade do uso das metodologias que empregam a elaboração de desenhos na pesquisa sobre a criação de sentido na mudança organizacional e identificar os aparentes benefícios e limitações de sua aplicação.

\section{a) Os tipos de organizaç̃os estudadas e o contexto das mudancas}

A pesquisa realizada por Vince e Broussine teve como foco a observação de seis organizações britânicas do setor público, compreendendo a administração de governo local e serviços de saúde. As seis organizações vinham passando por mudanças que atingiam todo o setor público do Reino Unido. Esse contexto compreendia como principais características:

- mudanças na estrutura de algumas funções importantes nas organizações, como, por exemplo, a de comprador;

- introdução do rigor da competição no setor público;

- ênfase crescente no desempenho;

- separação de processos políticos e gerenciais;

- crescimento da visão de managerialism nos serviços públicos;

- questionamento crescente sobre a validade de se manterem os serviços públicos;

- cortes de recursos;

- incertezas devidas a propostas de reestruturação do serviço público.

Por sua vez, a pesquisa realizada por Silva e Vergara procurou focalizar uma importante empresa estatal brasileira do setor de geração e transmissão de energia elétrica. A empresa vinha enfrentando, ao longo dos últimos oito anos, a expectativa de passar por um processo de privatização. Em função dessa expectativa, muitas medidas vinham sendo adotadas nos últimos tempos, visando preparar a empresa para a concretização desse processo em um futuro próximo, entre as quais: 
- sucessivos programas de aposentadoria e desligamento voluntário, compreendendo benefícios adicionais, o que provocou a saída de um número considerável de profissionais experientes;

- por tratar-se de uma empresa com forte ênfase tecnológica, essa perda de pessoas vinha ocasionando problemas como: elevação do risco nas operações; falta de profissionais em determinadas posições técnicas fundamentais; sobrecarga de trabalho em alguns setores de grande importância para a operação;

- reorganização de algumas áreas, em função de uma provável divisão da empresa após a privatização, bem como da provável fusão de alguns setores com similares de outras empresas do setor elétrico;

- corte de investimentos.

Uma característica marcante no contexto da empresa brasileira era também a grande quantidade de boatos na imprensa sobre o processo de privatização, sem que qualquer informação oficial tivesse sido emitida até o momento da realização da pesquisa.

\section{a) $O$ perfil dos participantes}

Em ambas as pesquisas, privilegiou-se a participação de pessoas que ocupavam posições de gerência nas organizações estudadas. A diferença mais significativa, apresenta-se no critério utilizado para a seleção dos participantes, em função do nível hierárquico do gerente na pirâmide da organização:

- No estudo de Vince e Broussine o grupo de participantes foi composto de 86 gerentes, sendo 37 do nível senior e 49 do nível intermediário

- No estudo de Silva e Vergara, participaram 165 gerentes de dois níveis intermediários imediatamente subseqüentes na escala hierárquica da empresa, sendo 75 do nível mais elevado (gerência senior, localizada imediatamente abaixo do nível de diretoria) e 90 do nível inferior (gerência operacional).

\section{c) A metodologia da aplicacão dos desenhos}

Vince e Broussine utilizaram uma metodologia composta de duas etapas:

- Primeira etapa: workshops distintos, com grupos compostos exclusivamente de gerentes senior ou de gerentes intermediários. Nesses workshops, pediu-se a cada participante que elaborasse um desenho, não acompanhado de texto, expressando seus sentimentos com relação às mudanças que vinham sendo realizadas. No verso da folha, pedia-se que cada participante, individualmente, comentasse o seu desenho. Após essa análise individual, os desenhos foram discutidos com o grupo;

- Segunda etapa: encontros de grupos mistos, compreendendo gerentes do nível senior e do nível intermediário, para discussão dos desenhos e dos comentários (registrados em flipcharts), obtidos na primeira etapa. As discussões dessa etapa foram registradas com o auxílio de gravador.

Talvez aí residam as diferenças mais significativos entre os dois estudos. No caso do trabalho de Silva e Vergara, a pesquisa foi desenvolvida como parte integrante de um programa de 
desenvolvimento gerencial. As informações utilizadas para compor o diagnóstico refletiram as percepções dos participantes e foram coletadas em duas fases distintas do desenvolvimento da disciplina que versava sobre Gestão de Pessoas - uma fase tutorial e uma fase presencial, as quais podem ser assim descritas:

- Fase tutorial - $\mathrm{Na}$ fase tutorial, os participantes desenvolveram estudos individuais preliminares aos encontros presenciais do programa de desenvolvimento gerencial, respondendo a perguntas baseadas na leitura de cinco textos indicados, sobre as características culturais da organização.

- Fase presencial - Esta fase foi constituída de encontros em sala de aula, nos quais cada grupo, composto exclusivamente de pessoas do mesmo nível gerencial, foi levado, durante dois dias, à exposição mais detalhada das idéias propostas para a mudança organizacional. Em cada grupo, na abertura da fase presencial, foi solicitado aos participantes, subdivididos em grupos de 5 pessoas, que elaborassem um desenho que refletisse a forma como eles percebiam a relação entre a empresa e seus empregados, no contexto das mudanças que vinham acontecendo e que se anunciavam para um futuro próximo. As imagens foram, então, debatidas com todo o grupo de 25 participantes, buscando a interpretação de seu significado. Com a finalidade de colher também as impressões mais racionais, ainda ao longo da fase presencial, foi submetido, a cada participante, um questionário de pesquisa, versando sobre diferentes dimensões da organização, relativas à cultura predominante e ao clima organizacional: Desenvolvimento das competências organizacionais; Envolvimento, comprometimento e moral das pessoas; Processo de tomada de decisão; Estrutura / infra-estrutura da organização; Necessidade da organização mudar; Comunicação / fluxo de informação; Trabalho em equipe; Desenvolvimento de competências individuais / treinamento; Processo de avaliação de desempenho das pessoas; Gerência de conseqüências, reconhecimento e motivação; Oportunidades individuais; Satisfação com o trabalho; a forma como são conduzidos os processos de gestão de pessoas.

\section{d) Os principais sentimentos e percepcões revelados com o auxílio dos desenhos}

Os resultados da aplicação da metodologia utilizada por Vince e Broussine revelam uma mistura de percepções otimistas, tais como a oportunidade de transformação pessoal e organizacional, e sentimentos pessimistas, como a ansiedade, o medo, a percepção de risco e a revolta com relação às mudanças. Um aspecto importante observado pelos autores é de que muitas vezes essa dualidade de sentimentos é manifestada em um mesmo desenho. Entre os sentimentos e percepções mais negativos revelados, estão:

- medo das consequiências das mudanças para os indivíduos e para a organização, em termos de sua identidade, objetivos e valores;

- sensação de que a organização é atingida por uma grande força externa (imagem de um maremoto, de uma demolição);

- ansiedade pela perda de algo fundamental;

- dificuldade de lidar com um significado diferente de serviço público;

- sentimento de impotência, debilidade, diante da mudança;

- sentimento de desestabilização do auto-conceito; 
- visão da mudança como uma etapa difícil a ser enfrentada, para se atingir a estabilidade desejada;

- sentimento de que para chegar a esse ideal de estabilidade muitas casualidades acontecerão e alguns não sobreviverão às mudanças;

- sentimento de que esse ideal de estabilidade talvez nunca seja alcançado;

- manifestações de revolta.

Do mesmo modo, na pesquisa desenvolvida por Silva e Vergara revelam-se também sentimentos e percepções consideradas pelos participantes como positivos e negativos. Nesse caso, no entanto, é rara a ocorrência da ambiguiidade de sentimentos revelada em um mesmo desenho. No resultado do trabalho de produção de cada grupo, surge, em geral, uma imagem predominantemente positiva ou predominantemente negativa.

As principais percepções que se manifestam nos desenhos e que foram consideradas negativas na análise realizada pelos participantes foram:

- incerteza quanto ao futuro;

- falta de um direcionamento claro a ser seguido;

- distância da cúpula da organização;

- rompimento de uma relação entre as pessoas e a organização, antes sólida;

- ameaça de rompimento de uma relação sólida entre as pessoas, em função da expectativa de cisão da empresa;

- impressão de que a mudança está sendo imposta por uma grande ameaça externa;

- impressão de que a empresa não está totalmente preparada ou não dispõe de condições ideais para mudar;

- $\quad$ sentimento de que parece não haver saída da crise;

- crença de que muitas pessoas não dispõem de condições de sobreviver às mudanças ou de que as condições não são iguais para todos;

- constatação de que há pessoas em pânico que não se engajam na luta pelo bem comum;

- percepção de que há um certo imobilismo por parte das pessoas na organização, mesmo diante das ameaças concretas;

- observação de atitudes individualistas acontecendo;

- sentimento de que nem todos têm o mesmo a perder;

- impressão de que a organização, antes sólida, está perdendo sua força;

- crença de que a verdade está sendo escondida dos funcionários.

Como percepções positivas, emergem da análise dos desenhos realizada pelos participantes:

- constatação de que há um grupo de pessoas leais à organização, que se mantém trabalhando para que ela não perca o rumo no processo de mudança, de que há um grupo de pessoas que se mantém unido em seus esforços pelo sucesso da organização e de todos; 
- sentimento de que a competência das pessoas pode ajudá-las a manterem-se firmes diante da mudança;

- crença de que a mudança não representará o fim da organização e de que, da mudança, pode nascer uma organização melhor.

\section{Conclusões}

Comparados os resultados obtidos nos dois estudos, pode-se observar que, na metodologia empregada por Vince e Broussine (1996), na qual foi adotada uma dinâmica de criação individual de desenhos, os tipos de sentimentos e percepções revelados são predominantemente de natureza individual. Por outro lado, na metodologia empregada por Silva e Vergara (1999), na qual os desenhos foram elaborados e discutidos exclusivamente em grupo, os resultados apontam para sentimentos e percepções que dizem respeito predominantemente a aspectos de relacionamento e de atitudes coletivas.

Possivelmente, essa constatação deve-se ao fato de que, no caso dos desenhos criados de modo coletivo, não se proporcionou ao indivíduo a oportunidade de refletir de modo mais intenso sobre seus próprios sentimentos durante a aplicação da dinâmica. No entanto, é possível que a necessidade de negociação do grupo, em torno da construção de uma única imagem que refletisse do modo mais fiel as percepções e sentimentos de todos, tenha aberto um espaço importante para a reflexão conjunta, acerca dos efeitos da mudança sobre as relações pessoais e os comportamentos individuais face ao outro.

Em ambos os casos, no entanto, os desenhos revelam sentimentos referentes à organização como um todo. E essa organização, que é retratada lado a lado com os indivíduos nas diversas imagens construídas, demonstra, em muitas situações, ter uma face humana, vontade própria, sentimentos, alegrar-se e sofrer com as mudanças, como as pessoas sofrem. Em outras palavras, em ambos os estudos, a representação que se constrói da organização como um todo é a de um outro para quem as pessoas individualmente e/ou coletivamente dirigem seus sentimentos, com a qual mantêm um diálogo, uma relação acompanhada de forte carga afetiva. Essa observação é coerente com as idéias de autores como Giddens (1984) e Taylor (1993), para quem o todo e a interação das partes, o macro e o micro da ação organizacional, não podem ser compreendidos senão como um único processo, representando, portanto, níveis da mesma realidade que se constróem mutuamente e de forma contínua.

Esses resultados sugerem também que os dois tipos de dinâmica, com a elaboração individual e coletiva dos desenhos, respectivamente, podem ser empregados de modo complementar, de maneira a que possam ser enfatizados os sentimentos e percepções relativos tanto à dimensão pessoal, quanto à dimensão relacional da mudança.

Algumas outras características importantes foram também reveladas, no emprego de cada uma das metodologias.

\section{a) No estudo realizado por Vince e Broussine (1996):}

- houve a percepção de que os desenhos realizados individualmente criaram condições para que os indivíduos manifestassem aspectos de natureza emocional que não manifestariam 
naturalmente em um discurso racional, o que, segundo os participantes, ajudou-os a melhor elaborar os seus próprios sentimentos com relação ao contexto da mudança;

- a possibilidade de discussão entre os dois diferentes níveis gerenciais foi percebida pelos participantes como uma oportunidade de estabelecimento de um tipo de diálogo entre esses dois níveis, difícil de ser conseguido em situações de trabalho.

Tais características revelam que, sob certos aspectos, a pesquisa que emprega a dinâmica da elaboração de desenhos não apenas abre um espaço para a manifestação de idéias, sentimentos e percepções que não seriam reveladas facilmente por outras técnicas de investigação, como também propiciam maior engajamento das pessoas, como indivíduos e como grupo, na reflexão produtiva que visa à busca de soluções para a problemática da mudança.

\section{b) No estudo realizado por Silva e Vergara (1999):}

- houve a percepção de que a elaboração de uma reflexão individual preliminar favoreceu o engajamento dos indivíduos na criação e discussão coletiva dos desenhos;

- a complementação da dinâmica dos desenhos com a aplicação e discussão do questionário sobre os itens organizacionais, foi de grande valia para que se pudesse estabelecer uma melhor compreensão do contexto da mudança, o que enriqueceu a interpretação mais apurada dos significados atribuídos aos desenhos pelos participantes.

Essas características observadas são coerentes com a afirmativa de Vince e Broussine (1996, p. 9-10), de que "os desenhos devem ser explicitamente colocados dentro de uma variedade de diálogos contextualmente específicos (intra/inter-pessoal e intra/inter-grupal) e vistos coletivamente como uma expressão do contexto".

É importante ressaltar, no entanto, que a presente análise não constitui uma comparação entre dois estudos absolutamente semelhantes, apenas replicados em contextos diversos. Trata-se de uma tentativa de observação da aplicabilidade de uma metodologia centrada na construção de imagens, tal como aquelas utilizadas em ambos os estudos, bem como do tipo de conhecimento que pode ser apreendido, a partir das variações metodológicas dessa aplicação.

Cabe destacar, ainda, algumas das principais diferenças existentes, em termos de metodologia empregada e conteúdo, entre os dois estudos alvos do presente trabalho, as quais podem resultar em limitações do próprio método de análise aqui empregado:

- há um contexto cultural que precisa ser levado em conta em cada um dos estudos, uma vez que trata-se de duas pesquisas realizadas em países com origens culturais distintas, respectivamente o Reino Unido e o Brasil;

- as duas pesquisas focalizam tipos distintos de organizações, que vivem contextos de mudanças específicos e momentos diferentes no processo e que não podem ser, portanto, plenamente comparados;

- não há uma homogeneidade em termos dos dados disponíveis sobre cada um dos estudos. No que tange à pesquisa desenvolvida pelos autores britânicos, toda a análise aqui realizada baseou-se exclusivamente nos dados divulgados no artigo em referência, enquanto a análise sobre os resultados do estudo brasileiro, por Silva e Vergara, estavam plenamente acessíveis, quando da análise comparativa. 
Ainda assim, as conclusões obtidas a partir da análise comparativa entre os dois estudos realizados, sugerem a possibilidade de desenvolvimento de outros métodos de aplicação de pesquisa utilizando desenhos para a compreensão do processo de construção de sentido nas situações de mudança organizacional. Dinâmicas semelhantes poderiam ser aplicadas com funcionários que atuam mais próximos da base organizacional, para quem os espaços disponíveis para discussão são, em geral, muito mais restritos e que podem, por isso mesmo, possuir muito menor motivação para expor seus sentimentos e percepções ao diálogo organizacional. Assim também, a aplicação desse tipo de dinâmica pode ser um importante instrumento de motivação para o estabelecimento de um diálogo mais intenso entre os gerentes e suas equipes, propiciando a reflexão conjunta e a construção integrada da ação na mudança.

\section{Referências Bibliográficas}

ALLAIRE, Y. FIRSIROTU, M. How to Implement Radical Strategies in Large Organizations. in TUSHMAN, M.L. et allis. The Management of Organizations, New York: Harper Collins, 1989.

ARMENAKIS, A.A. BEDEIAN, A.G. Organizational Change: a review of theory and research in the 1990's. Journal of Management, v.25, n.3, p.293-315, 1999.

CLARKE, A. GARSIDE, J. The Development of a Best Practice Model For Change Management. European Management Journal, v.15, n.5, October 1997.

DEMERS, C. Communication et Changement dans les Organisations. Communication et Organisation, n.3, p.94-127, mai 1993.

FORD, J.D. FORD, L.W. The Role of Conversations in Producing Change in Organizations. Academy of Management Review, Vol.20, No. 3, 1995, p.541-570.

GIDDENS, A. New Rules of Sociological Method, $2^{\text {nd }}$ ed., London: Hutchinson, 1993.

Press, 1984.

A. The Constitution of Society. Berkeley, California: University of California

GIROUX, N. Communication et Changement dans les Organisations. Communication et Organisation, n.3, p.9-18, mai 1993.

, N. DUMAS, D. Trois Modalités D'Intégration des Fusions/Acquisitions: l'intégration planifiée, l'intégration émergente et l'intégration conjointe. $V^{\text {ième }}$ Conférence de l'AIMS à l'École des HEC de Montréal, juin 1997.

ISABELLA, L.A. Evolving Interpretations as a Change Unfolds: how managers construe key organizational events. Academy of Management Journal, v.33, n.1, p.7-41, 1990.

KETS DE VRIES, M.F.R. BALAZS, K. Transforming the Mind-set of Organization. Administration and Society, v.30, n.6, January 1999.

KOTTER, J.P. Leading Change: why transformation efforts fail. Harvard Business Review, March-April 1995

NADLER, D. Concepts For The Management of Organization Change. in TUSHMAN, M.L. et allis. The Management of Organizations, New York: Harper Collins, 1989.

ROULEAU, L. Le <<Malaise〉> du Changment Intermédiaire en Contexto de Réorganisation: éclatement et renouvellement identitaires. Gestion - revue internationale de gestion. Montréal: HEC, v.24, n.3, p.96-101, Automne 1999.

SILVA, J.R.G. VERGARA, S.C. O Significado da Mudança: as percepções dos funcionários de uma empresa brasileira diante da expectativa de privatização. RAP - Revista de Administração Pública. Rio de Janeiro: Fundação Getúlio Vargas. Jan-fev/2000, n.1, v.34. 
TAYLOR, J.R. La Dynamique de Changement Organisationnel: une théorie conversation/texte de la communication et ses implications. Communication et Organisation, n.3, p.50-93, mai 1993.

VAN DE VEN, A.H. POOLE, M.S. Explaining Development and Change in Organizations. Academy of Management Review, v.20, n.3, p.510-540, 1995.

VINCE, R. BROUSSINE, M. Paradox, Defense and Attachment: accessing and working with emotions ans relations underlying organizational change. Organization Studies, n.17, v.1, p.1-21, 1996.

WALSH, J.P. UNGSON, G.R. Organizational Memory. Academy of Management Review, v.16, p.57-91, 1996.

WEICK, K.E. Sensemaking in Organizations, London: Sage, 1995.

, K.E. QUINN, R.E. Organizational Change and Development. $\underline{\text { Annual Review of }}$ Psychology, n.50, p.361-386, 1999. 